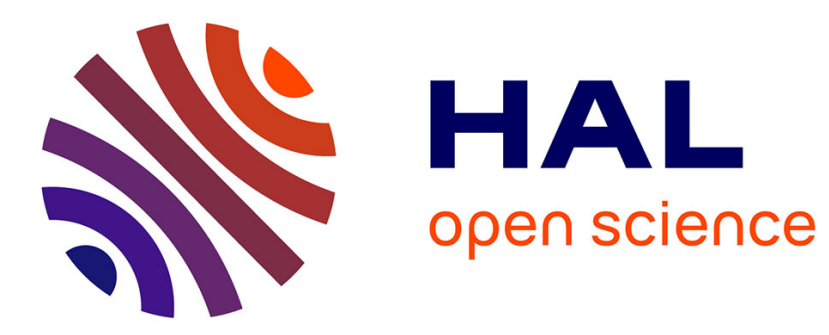

\title{
Measuring Uncertainty of Solvency Coverage Ratio in ORSA for Non-Life Insurance
}

Frédéric Planchet, Quentin Guibert, Marc Juillard

\section{To cite this version:}

Frédéric Planchet, Quentin Guibert, Marc Juillard. Measuring Uncertainty of Solvency Coverage Ratio in ORSA for Non-Life Insurance. European Actuarial Journal, 2012, 2 (2), pp.205-226. 10.1007/s13385-012-0051-7 . hal-01169220

\section{HAL Id: hal-01169220 \\ https://hal.science/hal-01169220}

Submitted on 21 Jul 2015

HAL is a multi-disciplinary open access archive for the deposit and dissemination of scientific research documents, whether they are published or not. The documents may come from teaching and research institutions in France or abroad, or from public or private research centers.
L'archive ouverte pluridisciplinaire HAL, est destinée au dépôt et à la diffusion de documents scientifiques de niveau recherche, publiés ou non, émanant des établissements d'enseignement et de recherche français ou étrangers, des laboratoires publics ou privés. 


\title{
Measuring uncertainty of solvency coverage ratio in ORSA for Non-Life Insurance
}

\author{
Version $^{1} 3.4,2012 / 04 / 27$ \\ Frédéric Planchet ${ }^{1,2, *}$, Quentin Guibert ${ }^{2, * *}$, Marc Juillard ${ }^{2, * *}$ \\ ${ }^{1}$ Institut de Science Financière et d'Assurances (ISFA) - Laboratoire SAF - Uni- \\ versité de Lyon - Université Claude Bernard Lyon 1, 50 avenue Tony Garnier, \\ 69366 Lyon Cedex 07, France. \\ ${ }^{2}$ WINTER \& Associés, 55 avenue René Cassin, 69009 Lyon, France.
}

\begin{abstract}
We apply a simple model to project the Solvency Capital Requirement (SCR) over several years, using an ORSA perspective, in order to assess the probability of achieving a solvency coverage ratio. To do so, we rely on a simplified framework proposed in Guibert [10] which provides a detailed explanation of the SCR. Then, we take into account temporal dynamics for liabilities, premiums and asset returns. Here, we consider guarantees in non-life insurance. This context, when simplified, allows us to use a lognormal distribution to approximate the distribution of the liabilities. It leads to a simple and tractable model for measuring the uncertainty of the solvency ratio in an ORSA perspective.
\end{abstract}

Keywords. ORSA, Risk Appetite, Solvency Capital Requirement projection, NonLife Insurance, Semi-analytical formula.

\section{Introduction}

With the introduction of the Own Risk Solvency Assessment (ORSA) under Pillar 2 of Solvency II (see Planchet and Juillard [12]), regulators require insurance companies to prove their ability to meet the regulatory margin requirements not only on the date of inventory but also prospectively, under the horizons of their strategic plans (see CEIOPS [5]). Accordingly, an insurer must be able to project the main characteristics of its balance sheet over a period of 3 to 5 years depend-

${ }^{1}$ The authors thank two referees whose comments have significantly improved this work. We also warmly thanks Pr. Ragnar Norberg for helpful comments and support.

* Frédéric Planchet is a professor at ISFA and an partner actuary at WINTER \& Associés. E-mail: frederic.planchet@univ-lyon1.fr.

** Marc Juillard and Quentin Guibert are R\&D actuarial consultants at WINTER \& Associés. 
ing on the duration of the strategic plan in addition to accounting for new business plans written over the period.

In particular, to prove the ability to cover the Solvency Capital Requirement (SCR), the insurer must be able to estimate the uncertainty associated with the future value of its assets and its liabilities in order to predict the probability of failure to cover the regulatory margin over the required duration.

This estimation is potentially tricky as it requires forecasting the main balance sheet items and regulatory ratios over the period chosen in order to approximate the distribution of the solvency coverage ratio at each date. Implementing a model at a level of detail similar to that used for inventory calculations is unsuitable here because of its complexity and its lack of potential robustness. The issues associated with a multi-year model approach are already described for example in Diers [6] and a more general framework for internal models and their potential use for multi-year calculus can be found in e.g., Liebwein [11]. The main drawback of these approaches is that they may potentially lead to very complex and intractable models. At this point, ORSA aims to provide for an insurance company a global view of the main risks it underwrites. As a consequence, the quantitative part of the ORSA framework must be easy to use and updated on a regular basis.

Therefore, we turn to more holistic approaches that model the risks through some state variables. To achieve this, one can use the general ruin theory (see for example Asmussen and Albrecher [2] for a complete overview of this topic). Thus, We choose to use a model inspired by the ruin theory taking into account financial risk, underwriting risk, and business risk.

In this paper, we propose an extension of Guibert et al. [10] by introducing a time dynamic to the aggregate model in a non-life insurance context.

The article is organized as follows: first, we describe in Section 2 a generic model which accounts for interactions between three types of risks - financial risk, underwriting risk, and business risk associated with the uncertainty of future premiums perceived in order to project the future SCR. In Section 3, we set the temporal dynamics for the key drivers of the balance sheet which can reasonably be used for non-life insurance and we deduce in Section 4, the way to value the solvency coverage ratios for future year. A numerical illustration is then given in 
Section 5. A separate Section (Section 6) is devoted to the possible extensions of the model in an ORSA context to reflect the provision of premium imposed by the standard model of Solvency II and to allow for multiple lines of business. The article ends by presenting adjustments to be made when using such a model for life and health insurance. These adjustments are only shown in theory; their development will be the subject of ensuing studies.

\section{General Structure and Notations}

Under a discrete time model, the periods are indexed by $t=0, \ldots, T$ to a time horizon of $T$. We take similar notations from Guibert et al. [10] in this paper, where $t$ refers to the end of the period [ $t, t+1$ [ (i.e. the time is considered to be discrete):

$-A_{t}$ denotes the market value of the theoretical assets invested in asset $S_{t}$ of return $R_{t}$; all financial interest is credited at the end of the period. The risk free discount rate used is assumed to be constant and is denoted as $r$.

$-L_{t}$ denotes the technical reserves and is equal to the sum of the best estimate $B E L_{t}$ and the risk margin $R M_{t}$, so $L_{t}=B E L_{t}+R M_{t} . D_{t}$ denotes the duration of the liabilities at time $t$.

$-P_{t}$ and $C_{t}$ represent the premiums earned and the claims paid, respectively. For simplicity, we assume that any fluctuations in these values occur at the end of the period.

$-\beta_{t}$ denotes the combined ratio at time $t$, such that for premiums collected $P_{t}$ we associate a cost of $\beta_{t} \times P_{t}$.

- $S C R_{t}$ denotes the margin requirement amount set by Solvency II and therefore equals the negative value of the $0.5 \%$ quantile of the one-year forecasted net assets.

Finally, we observe that the following variable plays a central role

$$
\chi_{t}=\frac{C_{t}+L_{t}-P_{t}}{1+R_{t}}
$$

We call $\chi_{t}$ the discounted net liability at time $t$.

The risk margin must be computed according to the Solvency II rules on the cost of capital: so we choose a cost of capital of $\alpha=6 \%$. For an analysis of the issues 
associated to account the risk margin for SCR calculation in a non-life framework, see Robert [14].

This relies on the balance sheet analysis proposed by Guibert et al. [10] observing that the basic relationship

$$
S C R=\operatorname{VaR}\left(\frac{C_{1}+L_{1}}{1+R_{1}}, 99.5 \%\right)-L_{0},
$$

which can be rewritten at any given instant, taking future premiums into account, as

$$
S C R_{t}=\operatorname{VaR}_{t}\left(\frac{C_{t+1}+L_{t+1}-P_{t+1}}{1+R_{t+1}}, 99.5 \%\right)-L_{t},
$$

with $L_{t}=B E L_{t}+R M_{t}$.

The subscript $t$ on the value at risk ( $\mathrm{VaR}$ ), expectations and variances indicates that the values are conditional on information available at time $t$. Furthermore, we need to make two assumptions to account for the risk margin. First, by retaining the assumption of proportionality between the Solvency Capital Requirement (SCR) and the best estimate (see Guibert et al. [10]), we observe that

$$
\chi_{t+1}=\frac{C_{t+1}+L_{t+1}-P_{t+1}}{1+R_{t+1}}=\frac{C_{t+1}+h_{t} \times B E L_{t+1}-P_{t+1}}{1+R_{t+1}}
$$

with $h_{t}=1+\alpha \times \frac{S C R_{t}}{B E L_{t}} \times D_{t+1}$. Second, this term is approximated in practice ${ }^{2}$ by

$$
h_{t}=1+\alpha \times \frac{S C R_{t}}{B E L_{t}} \times D_{t},
$$

to remove the randomness introduced by the presence of duration $D_{t+1}$ in the definition of $h_{t}$. Hence, the Equation (1) defining SCR becomes

$$
S C R_{t}=V a R_{t}\left(\frac{C_{t+1}+h_{t} \times B E L_{t+1}-P_{t+1}}{1+R_{t+1}}, 99.5 \%\right)-B E L_{t}-\alpha \times S C R_{t} \times D_{t},
$$

and therefore,

\footnotetext{
${ }^{2}$ This justifies index $t$ and not $t+1$.
} 


$$
S C R_{t}=\frac{\operatorname{VaR}_{t}\left(\frac{C_{t+1}+\left(1+\alpha \times \frac{S C R_{t}}{B E L_{t}} \times D_{t}\right) \times B E L_{t+1}-P_{t+1}}{1+R_{t+1}}, 99.5 \%\right)-B E L_{t}}{1+\alpha \times D_{t}} .
$$

This expression is not easy to handle as it is an implicit equation of $S C R_{t}$ which can only be solved numerically, as will be shown later.

To start with, the behavior of the various elements accounted for in this projection, such as the value of assets, value of liabilities, claims, premiums, etc., must first be specified.

\section{Defining the Dynamics of the Model}

The calculations are carried out in two stages. First, we specify the dynamics for the four risk factors appearing in the model: premiums, best estimate (past pricing risk), combined ratio (future pricing risk and risk of expenses), and assets return. Next, we deduce the expressions of other variables of interest, such as claims and asset value.

\subsection{Risk Factor Dynamics}

We assume that, conditionally on the information available at time $t$, the variables $B E L_{t+1}, P_{t+1}, \beta_{t+1}$ and $S_{t+1}$ (the asset with yield $\frac{S_{t+1}}{S_{t}}=1+R_{t+1}$ ) follow lognormal random walks,

$$
\begin{gathered}
P_{t+1}=P_{t} \times X_{p} \text { with } X_{p} \sim \mathcal{L} \mathcal{N}\left(\mu_{p}-\frac{\sigma_{p}^{2}}{2}, \sigma_{p}^{2}\right), \\
\beta_{t} \sim \mathcal{L} \mathcal{N}\left(\ln (\beta)-\frac{\sigma_{\beta}^{2}}{2}, \sigma_{\beta}^{2}\right), \\
B E L_{t+1}-\beta_{t+1} \times P_{t+1}=B E L_{t} \times X_{l} \text { with } X_{l} \sim \mathcal{L} \mathcal{N}\left(\mu_{l}-\frac{\sigma_{l}^{2}}{2}, \sigma_{l}^{2}\right), \\
S_{t+1}=S_{t} \times X_{a} \text { with } X_{a} \sim \mathcal{L N}\left(\mu_{a}-\frac{\sigma_{a}^{2}}{2}, \sigma_{a}^{2}\right),
\end{gathered}
$$


where $\beta$ is a fixed target combined ratio and the parameters $\sigma_{\beta},\left(\mu_{p}, \sigma_{p}\right)$, $\left(\mu_{l}, \sigma_{l}\right)$ and $\left(\mu_{a}, \sigma_{a}\right)$ describe the distribution of the independent lognormal risk factors.

The rate of change of reserves $\mu_{l}$ must be affected by discounting and the level of claims paid. We propose to retain the simple relation of $\mu_{l}=r+\ln (1-\varphi)$ with $\varphi$ a constant decrease in claims payable between two dates to take into account these effects. Based on this notation, the equation defining $B E L_{t+1}$ is

$$
B E L_{t} \times e^{-\frac{\sigma_{l}^{2}}{2}+\sigma_{l} \times \varepsilon_{t+1, l}}=e^{-r} \times\left(B E L_{t+1}-\beta_{t+1} \times P_{t+1}\right)+\varphi \times B E L_{t} \times e^{-\frac{\sigma_{l}^{2}}{2}+\sigma_{l} \times \varepsilon_{t+1, l}},
$$

or

$$
B E L_{t+1}-\beta_{t+1} \times P_{t+1}=B E L_{t} \times e^{r-\frac{\sigma_{l}^{2}}{2}+\sigma_{l} \times \varepsilon_{t+1, l}}-\varphi \times B E L_{t} \times e^{r-\frac{\sigma_{l}^{2}}{2}+\sigma_{l} \times \varepsilon_{t+1, l}},
$$

with $\varepsilon_{t+1, \beta}, \varepsilon_{t+1, p}, \varepsilon_{t+1, l}$ and $\varepsilon_{t+1, a}$ are independent Gaussian white noises.

The Equation (3) reflects the consumption of reserves in the run-off - the variation trend of the best estimate is caused by the effect of reduced discounting of the claims paid. By identifying the two terms in the equation, we find that the claims are equal to

$$
C_{t+1}=e^{r-\frac{\sigma_{l}^{2}}{2}+\sigma_{l} \times \varepsilon_{t+1, l}} \times \varphi \times B E L_{t}=\theta \times\left(B E L_{t+1}-\beta_{t+1} \times P_{t+1}\right),
$$

with $\theta=\frac{\varphi}{1-\varphi}$. On the basis of these assumptions, and in the absence of new premiums, the martingale property of the process of the best estimates holds,

$$
B E L_{t}=E_{t}\left(e^{-r} \times\left(C_{t+1}+B E L_{t+1}-\beta_{t+1} \times P_{t+1}\right)\right) .
$$

\subsection{Evolution Equations of Other Factors}

Once the processes describing the evolution of various balance sheet items are defined, we need to analyze the distribution of the discounted net liability $\chi_{t}=\frac{C_{t}+L_{t}-P_{t}}{1+R_{t}}$. In the absence of a risk margin, we get an expression of the form 


$$
\chi_{t+1}=\frac{(1+\theta) \times B E L_{t+1}-\left(1+\theta \times \beta_{t+1}\right) \times P_{t+1}}{1+R_{t+1}},
$$

with $\theta$ as defined in 3.1, which helps determine the distribution so as to calculate the SCR using the relation (2) presented in Section 2. In the presence of a risk margin, we use

$$
\chi_{t+1}=\frac{\left(h_{t}+\theta\right) \times B E L_{t+1}-\left(1+\theta \times \beta_{t+1}\right) \times P_{t+1}}{1+R_{t+1}},
$$

with $h_{t}$ as defined in Section 2. Since it leads to simpler calculation and in order to to avoid circularity dependence between the both quantities, the QIS5 (see CEIOPS [5]) computes the SCR without taking into account the risk margin effect. But this simplification leads to an overestimation of the SCR. As exact calculus can here be achieved, we choose to take the risk margin into account to avoid a bias in our model.

Once $S C R_{t}$ is determined, all other interest variables are easily obtained:

- The value of assets: $A_{t}=A_{t-1} \times\left(1+R_{t}\right)-C_{t}+P_{t}$,

- The value of liabilities: $L_{t}=B E L_{t}+R M_{t}=B E L_{t}+\alpha \times D_{t} \times S C R_{t}$.

Then, the solvency coverage ratio of the regulatory margin is calculated by

$$
s_{t}=\frac{A_{t}-L_{t}}{S C R_{t}} .
$$

However, we must first determine the distribution of $\chi_{t+1}$ conditional on the information available at time $t$. This will be discussed in the next Section.

\section{Calculating the Distribution of the Net Discounted Liability}

The random variable $\chi_{t+1}$ is a weighted sum of lognormal variables in the numerator over a lognormal variable in the denominator (see Equation (4)). The form of this distribution is not particularly simple due to the numerator and we can estimate this random variable by a lognormal distribution whose parameters are obtained by the method of moments (Fenton-Wilkinson approximation described in Fenton [9]). Hence, the ratio is approximated by a lognormal distribution as the denominator is assumed to be lognormal. 
This approximation of the net discounted liability leads to an implicit equation of $S C R_{t}$ easily resolvable compared to Equation (2).

\subsection{Distribution of the Net Liability}

The net liability $\chi_{t+1}^{N}$, corresponding to the numerator of $\chi_{t+1}$, is the sum of two lognormal variables minus a another lognormal variable

$$
\begin{aligned}
\chi_{t+1}^{N} & =\left(h_{t}+\theta\right) \times B E L_{t+1}-\left(1+\theta \times \beta_{t+1}\right) \times P_{t+1} \\
& =\left(h_{t}+\theta\right) \times B E L_{t} \times e^{\mu_{l}-\frac{\sigma_{l}^{2}}{2}+\sigma_{l} \times \varepsilon_{t+1, l}}+h_{t} \times \beta_{t+1} \times P_{t+1}-P_{t+1} .
\end{aligned}
$$

Upon dividing by $P_{t+1}$, we have

$$
\frac{\chi_{t+1}^{N}}{P_{t}}=\left(h_{t}+\theta\right) \times \frac{B E L_{t}}{P_{t}} \times e^{\mu_{l}-\mu_{p}-\frac{\sigma_{l}^{2}}{2}+\frac{\sigma_{p}^{2}}{2}+\sigma_{l} \times \varepsilon_{t+1, l}-\sigma_{p} \times \varepsilon_{t+1, p}}+h_{t} \times \beta_{t+1}-1,
$$

and we deduce than $\frac{\chi_{t+1}^{N}}{P_{t}}$ can be represented as $\frac{X+Y-1}{Z}$ with $X, Y$ and $Z$ lognormal variables. Consequently, studying if $\chi_{t+1}^{N}$ is lognormal can be reduced to studying if the variable $X+Y-1$ is lognormal, i.e., searching the range of parameters where the lognormal approximation is appropriate.

A large amount of literature is dedicated towards the approximation of the sum of lognormal distributions (see Fenton [9], El Faouzi and Maurin [8] or Schwartz and Yeh [16]). However, in situations where volatility is not too significant (see Dufresne [7]), we can use the lognormal approximation. It is well known that, for higher standard deviation values, this approximation tends to underestimate the mean and overestimate the variance of the sum of lognormal distributions. This approximation can also be applied when taking the difference of lognormal distributions, but it is only valid for situations where $X+Y \gg 1$, i.e., the premiums are relatively small in comparison to stock commitments to ensure a positive numerator with high probability ${ }^{3}$.

\footnotetext{
${ }^{3}$ In the case of a negative numerator with high probability (e.g. new product), this ap-
} proximation can be applied by considering the opposite of the numerator. 
The validation procedure of $X+Y-1 ; \quad$ with $\quad X \sim \mathcal{L} \mathcal{N}\left(\mu_{X}-\frac{\sigma_{X}^{2}}{2}, \sigma_{X}^{2}\right)$, $Y \sim \mathcal{L N}\left(\mu_{Y}-\frac{\sigma_{Y}^{2}}{2}, \sigma_{Y}^{2}\right)$, as a lognormal variable is carried out by Jarque-Bera (Bera and Jarque [3]) and Anderson-Darling tests (Anderson and Darling [1]). $X+Y-1$ is said to be approximately lognormal if the p-value is greater than $5 \%$. Naturally this lognormal approximation depends on the values of the parameters $\mu_{X}, \mu_{Y}$, $\sigma_{X}$ and $\sigma_{Y}$. By denoting $C=\sqrt{\sigma_{X}^{2}+\sigma_{Y}^{2}}$ which is a simple criterion to handle, we compute the set of parameters where the lognormal approximation is justified. On Fig. 1. Limit of the, we provide the upper limit of the criterion $C$ as a function of $\mu_{X}$ and $\mu_{Y}$ for $X+Y-1$ to be $\log$ normally distributed.

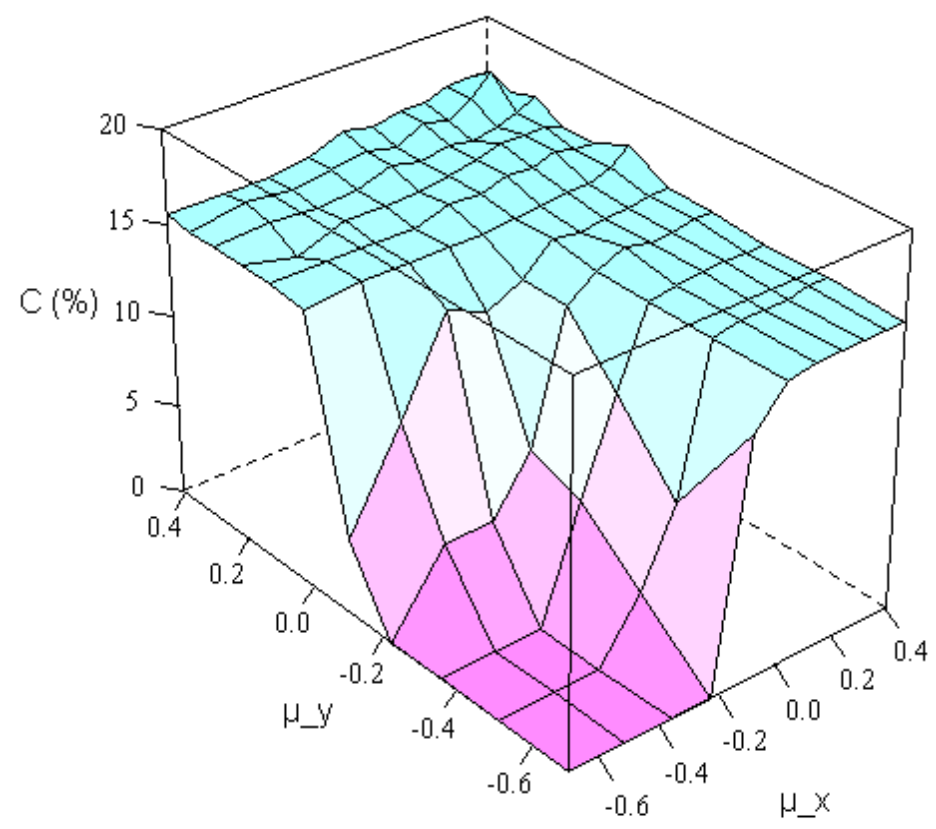

Fig. 1. Limit of the set of admissible parameters for lognormal approximation

Since $Z$ is also lognormal, the random variable $\frac{X+Y-1}{Z}$ has an approximate lognormal distribution provided that the parameters satisfy numerically the condition illustrated on Fig. 1. Limit of the set of admissible parameters for lognormal approximationIn practice, this approximation should be validated on a case by case basis following example of validation process given in Section 5.2. 


\subsection{Approximation of the Net Discounting Liability}

In approximating the variable $C_{t+1}+B E L_{t+1}-P_{t+1}$ conditionally to the information available at time $t$ by a lognormal distribution attained by the method of moments, we find that the solvency coverage ratio $\chi_{t+1}$ can be approximated by a lognormal distribution. Therefore, we have an explicit expression of the quantile of $\chi_{t+1}$, as a lognormal distribution of $X$ with parameters $(\mu, \sigma)$, we have

$$
x_{p}=\operatorname{VaR}_{p}(X)=\exp \left(\mu+\sigma \times \Phi^{-1}(p)\right)
$$

where $\Phi$ is the distribution function of the standard normal distribution.

Calculate this quantile comes down to calculating the parameters $(\mu, \sigma)$ of the lognormal approximation of the solvency coverage ratio $\chi_{t+1}$. As the mean $m$ and variance $v^{2}$ of the lognormal distribution $X$ are given respectively by

$$
m=\exp \left(\mu+\frac{\sigma^{2}}{2}\right) \text { and } v^{2}=\left(e^{\sigma^{2}}-1\right) \times m^{2}(\text { see Saporta }[15])
$$

and using the method of moments, we get an explicit expression of $S C R_{t}$ in terms of $B E L_{t}, \beta_{t}, P_{t}$ and $1+R_{t}$.

To do so, we observe that the variance of the underlying normal distribution is calculated simply by using the coefficient of variation of the lognormal distribution

$$
\sigma^{2}=\ln \left(1+\omega^{2}\right)
$$

where $\omega=\frac{v}{m}$. Once this parameter is known, the expectation of the underlying normal distribution is calculated using $\mu=\ln (m)-\frac{\sigma^{2}}{2}$ or $\mu=\ln \left(\frac{m}{\sqrt{1+\omega^{2}}}\right)$.

The calculation of the conditional expectation and the conditional variance of the variable $\left(h_{t}+\theta\right) \times B E L_{t+1}-\left(1+\theta \times \beta_{t+1}\right) \times P_{t+1}$ is described in Appendix 8.1 and then we use a lognormal approximation with the followings parameters

$$
\sigma_{t}^{2}=\ln \left(1+\omega_{t}^{2}\right), \mu_{t}=\ln \left(\frac{\left(h_{t}+\theta\right) \times B E L_{t} \times e^{\mu_{t}}-\left(1-h_{t} \times \beta\right) \times P_{t} \times e^{\mu_{p}}}{\sqrt{1+\omega_{t}^{2}}}\right) .
$$


Finally, the distribution of the net discounted liability

$$
\chi_{t+1}=\frac{\left(h_{t}+\theta\right) \times B E L_{t+1}-\left(1+\theta \times \beta_{t+1}\right) \times P_{t+1}}{1+R_{t+1}},
$$

conditional on information at time $t$, is lognormal with the parameters of the underlying normal distribution

$$
\mu_{t}(\chi)=\mu_{t}-\mu_{a}+\frac{\sigma_{a}^{2}}{2}, \sigma_{t}^{2}(\chi)=\sigma_{t}^{2}+\sigma_{a}^{2}
$$

We finally derive from Equation (2) the following implicit equation of $S C R_{t}$

$$
S C R_{t}=\frac{1}{1+\alpha \times D_{t}}\left(\exp \left(\mu_{t}(\chi)+\sigma_{t}(\chi) \times \Phi^{-1}(99.5 \%)\right)-B E L_{t}\right) .
$$

Actually, $\mu_{t}(\chi)$ and $\sigma_{t}^{2}(\chi)$ are dependent on $S C R_{t}$ because $\chi$ depends on $h_{t}$ as defined in Section 2. This equation can only be solved numerically using some standard root-finding algorithms.

The value of assets is determined using $A_{t}=A_{t-1} \times\left(1+R_{t}\right)-C_{t}+P_{t}$ and finally, the amount of liabilities is given by $L_{t}=B E L_{t}+R M_{t}=B E L_{t}+\alpha \times D_{t} \times S C R_{t}$.

\section{A Simple Example of Implementation in ORSA}

In this Section we illustrate the above model in the context of establishing an ORSA process. The purpose of this example is to show that the model fits naturally within this framework and provides the quantitative requirements.

This Section presents the application of the model to a non-life insurance company, in a more general context of an $\mathrm{ORSA}^{4}$ process (as defined in Solvency II). This process consists of the following step:

- Step 1: Define the risk appetite of the company, the risk metrics and the horizon used to manage the company,

- Step 2: Compute these metrics and check if the risk appetite constraints are satisfied on the first projection year: this is a necessary condition to meet the risk appetite constrains,

\footnotetext{
${ }^{4}$ A description of the general ORSA structure can be found in Planchet and Juillard [12].
} 
- Step 3: Defined operational risk limits in accordance with the step 2 results,

- Step 4: Check if the risk appetite constrains are verified on the duration of the strategic plan,

- Step 5: Perform a sensitive analysis to assess the robustness of the strategic plan.

The model is programmed with the $\mathrm{R}$ software ( $\mathrm{R}$ Development Core Team [13]) and the code is available upon request. We work with a sample size of 5000.

\subsection{Description of the Company}

We consider, for our example, an insurance company selling a single health contract with the following general structure:

- average combined ratio of $\beta_{0}=100 \%$,

- average premium sales of $C_{0}=€ 75$ million,

- asset allocation consisting of $20 \%$ stock and $80 \%$ bonds (1 year treasury bonds),

- initial SCR coverage ratio of $s_{0}=204 \%$,

- the strategic plan is to maintain the current risk profile of the structure (i.e. stable sales and allocation),

- to simplify our example below, we assume that the duration of liabilities is stable over time $D_{0}=2$ (this assumption is particularly appropriate for health care contracts). This value of $D_{0}$ is based on a statistical analysis of a French insurance portfolio (medical expenses).

Based on a statistical analysis of its portfolio, the company confirmed lognormal characteristics of its risks, whose respective parameters are as follows:

- mean and volatility of the premiums: $\mu_{p}=0, \sigma_{p}=1 \%$,

— volatility and decrease speed of claims: $\sigma_{l}=10 \%, \varphi=80 \%$,

- volatility and target value of the combined ratio: $\sigma_{\beta}=2 \%, \beta=100 \%$,

- mean and volatility of the asset: $\mu_{a}=3,6 \%, \sigma_{a}=6,3 \%$.

Upstream of the numerical application and after setting a base scenario in the following Section, we validate the lognormal distribution of the key risk driver $\chi_{t+1}$. After that, we describe the ORSA process by using the model as described above. 


\subsection{Validation of the Lognormal Approximation}

After checking the parameters satisfy the test defined in Section 4.1, we assess the fit of the lognormal approximation of the conditional distribution of $\chi_{t+1}$ by comparing the approximated lognormal distribution with the empirical distribution obtained by simulation. That is, we use simulations to compute the empirical distribution of (see Section 3.2)

$$
\chi_{t+1}=\frac{\left(h_{t}+\theta\right) \times B E L_{t+1}-\left(1+\theta \times \beta_{t+1}\right) \times P_{t+1}}{1+R_{t+1}} .
$$

The resulting empirical distribution of $\chi_{1}$ is plotted in Fig. 2

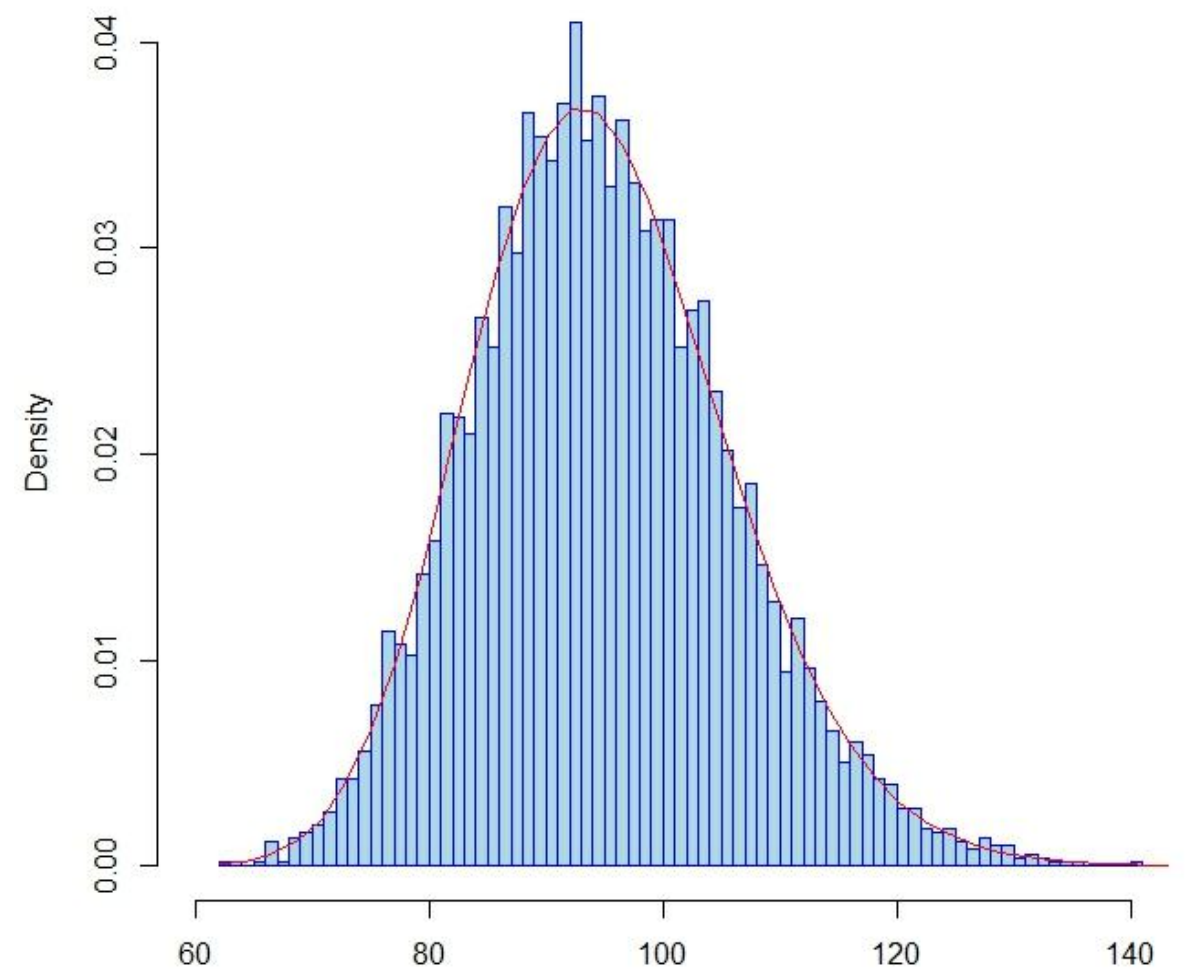

Fig. 2. Comparison of the histogram of the simulated and the fitted density of the net discounted liability

Thus, the fit seems graphically (Fig. 2) correct. Using the Jarque-Bera test (Bera and Jarque [3]), generally intended for large sample sizes, to match $\ln \left(\chi_{1}\right)$ to a normal distribution, we get a p-value of 35\%. Therefore, the lognormal approximation seems acceptable.

The base scenario gives the following results (Table 1) of solvency coverage ratio for years 0 through 5 
Table 1. Statistics of the evolution of solvency coverage ratio

\begin{tabular}{lllllll}
\hline Projection year & Min & 1st Quartile & Median & Mean & 3rd Quartile & Max \\
\hline 0 & 2.037 & 2.037 & 2.037 & 2.037 & 2.037 & 2.037 \\
1 & 0.5236 & 1.7850 & 2.0600 & 2.0540 & 2.3200 & 3.4800 \\
2 & -0.1324 & 1.7330 & 2.0990 & 2.1240 & 2.5100 & 4.3880 \\
3 & -0.2213 & 1.7040 & 2.1690 & 2.1940 & 2.6700 & 5.2240 \\
4 & -0.1557 & 1.6790 & 2.2420 & 2.2650 & 2.8160 & 5.5960 \\
5 & -0.6712 & 1.6800 & 2.3060 & 2.3450 & 2.9630 & 6.1900 \\
\hline
\end{tabular}

\subsection{Choice of Risk Appetite}

As part of the risk appetite process, the Board of Directors aims to control two indicators: the solvency and the profitability of its stockholders' equity. The interpretation of this risk appetite is set out below:

- to present $95 \%$ of the time an SCR coverage ratio of $130 \%$ over 5 years (which is the duration of the strategic plan),

- to present $80 \%$ of the time a loss on return on equity (measured by $\left.W_{t}=1-\frac{A_{t}-L_{t}}{A_{t-1}-L_{t-1}}\right)$ of $13.5 \%$ over at least 1 year.

On the basis of the projection model proposed, the empirical correspondence between the company's strategic plan and its policy for risk appetite is initially verified by its structure:
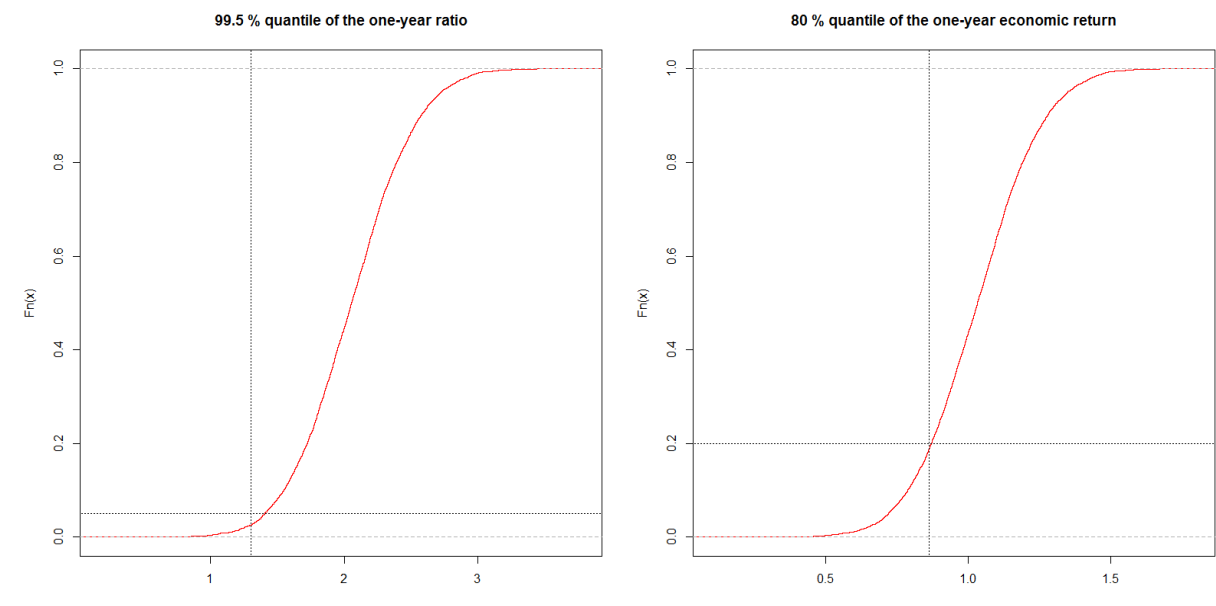

Fig. 3. Empirical distribution function of the one-year solvency ratio and the equity return

The graphs above (Fig. 3) represent the empirical cumulative distribution functions of the one-year solvency coverage ratio and the one-year return of equity. We also plot the risk appetite constrains with the vertical lines at $130 \%$ and $86.5 \%$ (the limits on SCR coverage ratio and return of equity) and the horizon lines at $5 \%$ and $20 \%$, which are the limit on the probability. The graphs show that while 
the strategic plan can meet the risk appetite constraints applied by the company since the empirical distributions are lower the intersection points. This first step helps avoiding performing calculation on the duration of the strategic plan and save computing time, but it does not provide operational limits as it consists of points rather than interval allocations. To address this issue, two solutions are available:

- to test several types of arbitrarily fixed allocations,

- to define the set of allocations able to meet the risk appetite as defined by company policy.

Testing arbitrarily a set of strategic allocations is not advisable in a risk appetite context since this process aims to seek optimal strategies while remaining within the feasible risk tolerance set by the company. The company therefore has to define the set of acceptable allocations representing the 5\% quantile of a one-year solvency coverage ratio over the set of all possible allocations. Fig. 4 represents the set of strategic allocations (defined by the percentage of the portfolio invested in bonds) and the amounts of future premiums for which the SCR coverage ratio exceeds $130 \%$ in $95 \%$ of cases.

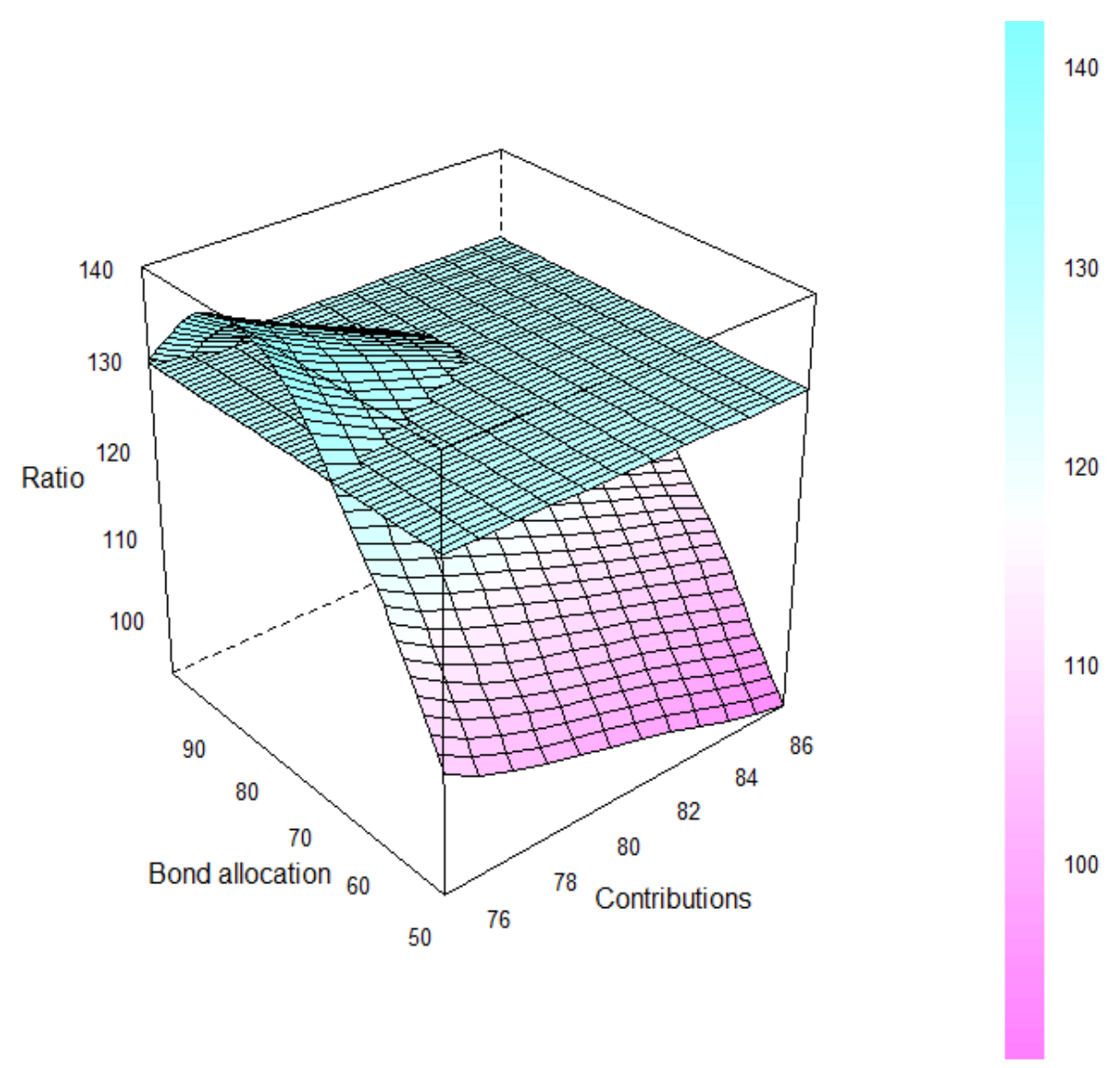


Fig. 4. Evolution based on the strategic allocation (Bond allocation in $\%$ and Contributions in $€$ million) of the constraint on SCR

The Fig. 4 shows that:

- the greater the company's volume of premiums, the lower its share allocation (this explains the concept of capital transfer between risks),

- certain amounts of premiums appear to be a minimum share allocation constraint as well as an inability to comply with SCR constraints.

At first, the company analyzes the restrictions on the return on investment of stockholders' equity and then it defines the investment limits. The Fig. 5 shows the set of strategic allocations (defined by the percentage of the portfolio invested in bonds) and the amounts of future premiums for which the return on equity exceeds $86.5 \%$ in $80 \%$ of cases.

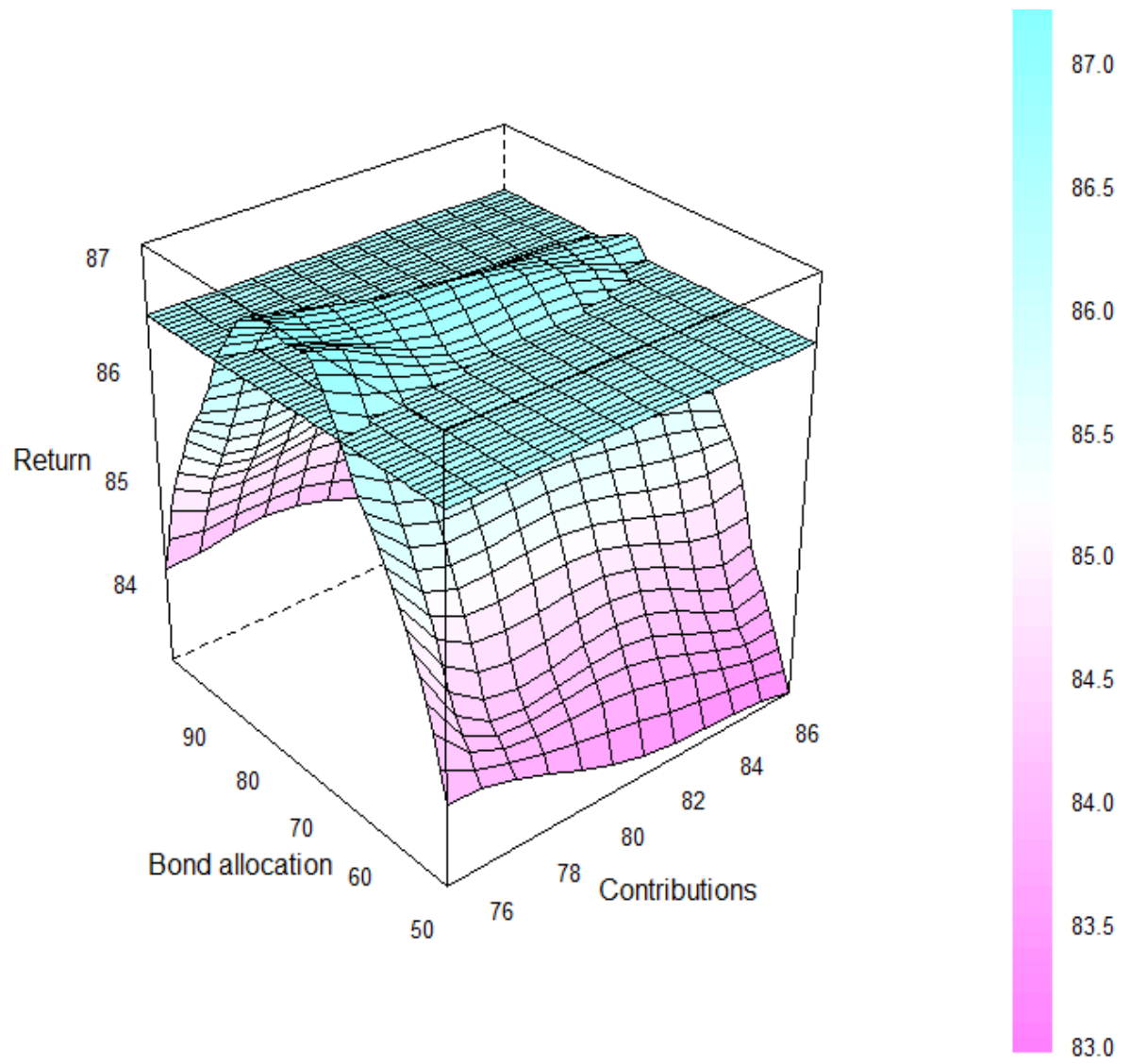

Fig. 5. Evolution of strategic allocation (Bond allocation in $\%$ and Contributions in $€$ million) of performance constraint

The graph above (Fig. 5) shows that the "return" dimension (i.e. the evolution of the return on investment) defines the minimum limits of risky investments, while 
the "solvency" dimension (i.e. the evolution of the solvency coverage ratio described in Fig. 4) mainly shows the maximum investment constraints.

At this stage, the company must first express its risk preference - it must decide whether it prefers to allocate its risk to assets or to liabilities. Generally, the fact that risk's liabilities are related to business development lead to concentrate the risk capital on liabilities. Thus, the company initially chooses the operational limits concerning pricing risk, marketing between $€ 75 \mathrm{~m}$ and $€ 78 \mathrm{~m}$ of premiums over the 5 upcoming years (or an increase of about 5\%). Secondly the company adapts the limits on assets as the risk appetite constrains are verified.

Given the changes in risk based on the premium amounts, the constraints related to the target allocations are based on a target premium of $€ 78 \mathrm{~m}$.

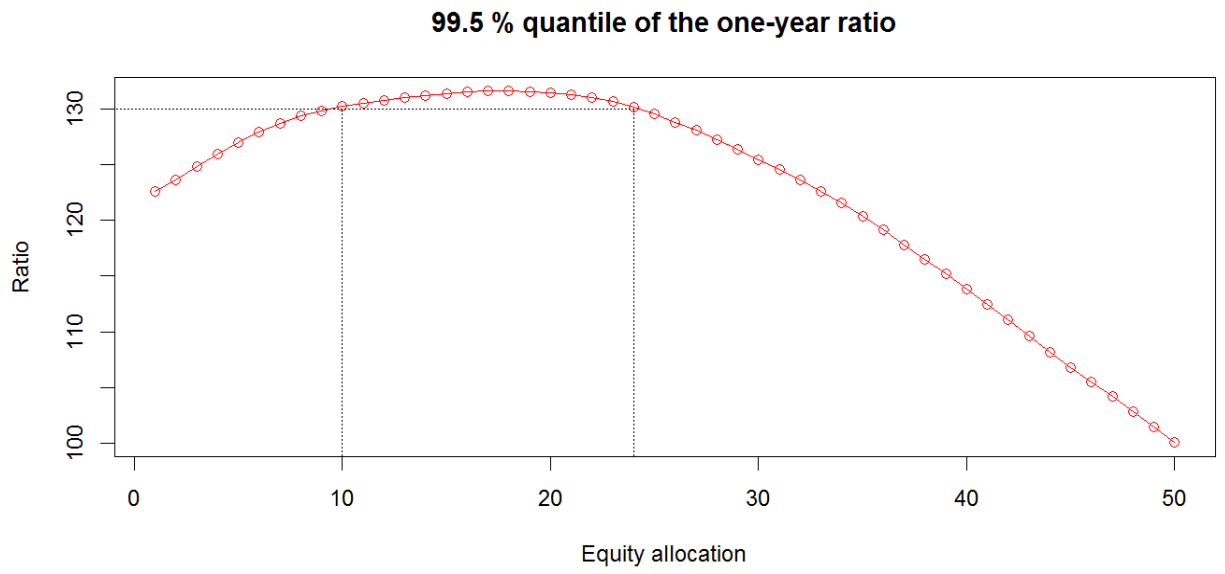

Fig. 6. Operational limit shares caused by a constraint on the SCR

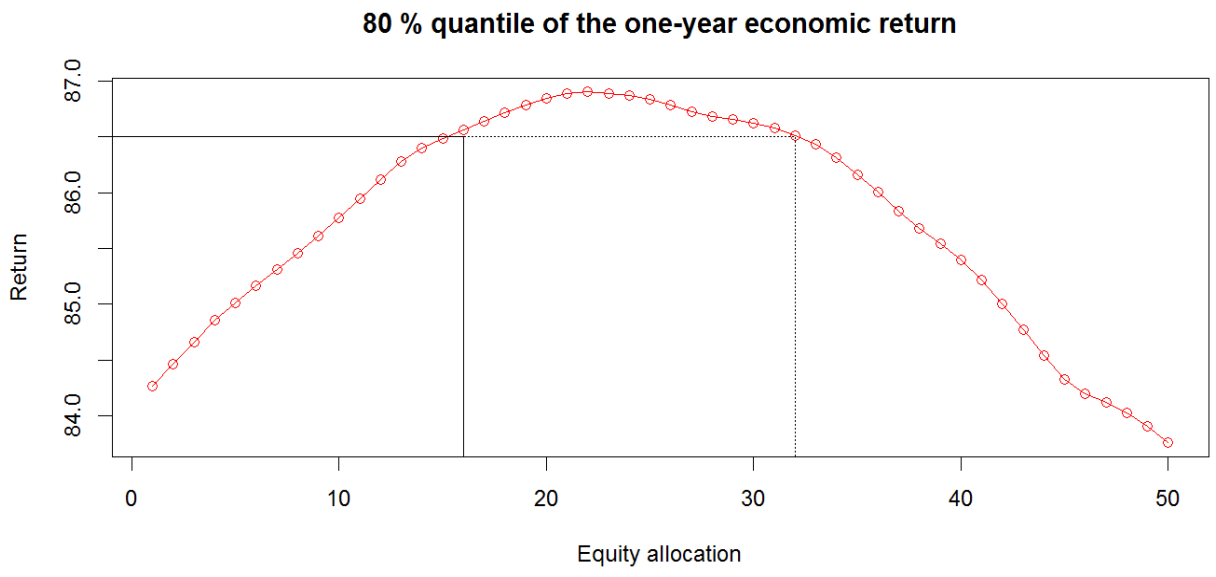

Fig. 7. Operational limit shares caused by a constraint on the yield 
Fig. 6 and Fig. 7 show how the SCR coverage ratio at 95\% and the return on equity at $80 \%$ evolve according to the equity allocation chosen with $€ 78 \mathrm{~m}$ of premiums and give the range of allocation percentages that satisfy the risk appetite constrains on the first year. We deduce that keeping within the one year SCR constraint for a $€ 78 \mathrm{~m}$ sale of premiums involves retaining an equity allocation between $10 \%$ and $24 \%$, and that a compliance with the constraint relative to the one year return of investment requires retaining an equity allocation between $16 \%$ and $32 \%$. The company decided to set the following operational limits:

— earning between $€ 75$ to $€ 78$ million of premiums,

- allocating equity between $16 \%$ and $24 \%$.

In order to finish the risk appetite process, confirming compliance with SCR constraints over the duration of the strategic plan (i.e. 5 years) is necessary. Then, the model is revived by retaining the upper bound risk limits as well as a 5 year forecast as the strategic plan. As, we consider an annual 95\% probability, the quantile level for the year " $\mathrm{n}$ " is $0.95^{n}$.

Table 2. Evolution of the quantile of the solvency coverage ratio

\begin{tabular}{lll}
\hline Projection year & Quantile level & Solvency coverage ratio \\
\hline 1 & $95 \%$ & 1.31 \\
2 & $90 \%$ & 1.3 \\
3 & $85 \%$ & 1.33 \\
4 & $81 \%$ & 1.41 \\
5 & $77 \%$ & 1.52 \\
\hline
\end{tabular}

Table 2 shows that the operational limits can meet the risk appetite over the entire duration of the strategic plan. The constraint on the return of investment is verified as it lasts 1 year.

We should also note that keeping within the constraints over the entire duration of the strategic plan is not acquired beforehand; the operational limits are set after analyzing one year results. Thus, a (relatively small) breach can occur and would involve reviewing operational limits. The development of the distribution of the coverage ratio over 5 years is presented in Fig. 8. 


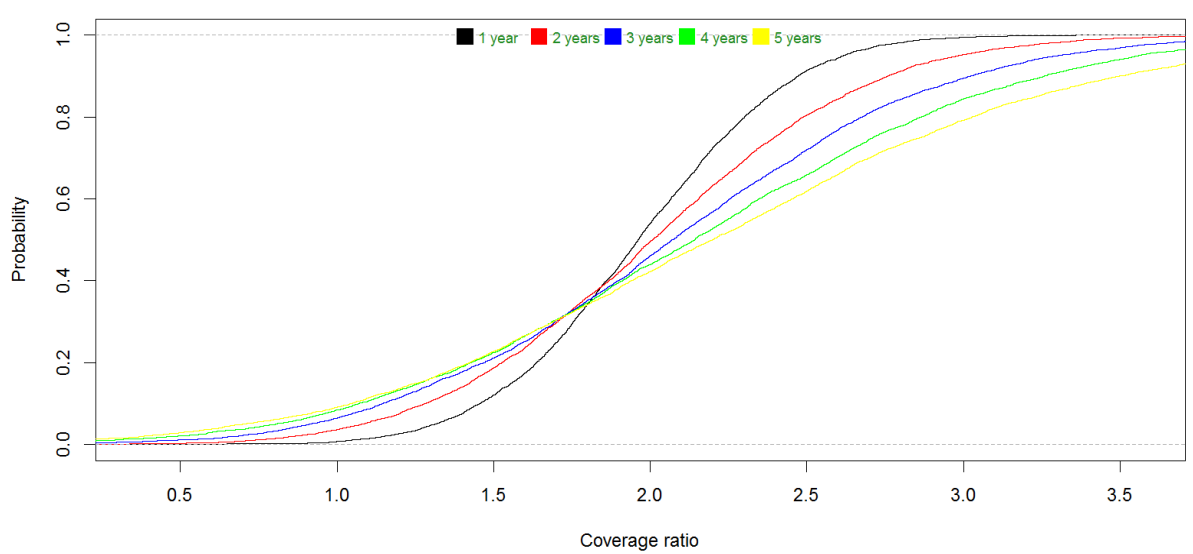

Fig. 8. Analysis of compliance with the risk appetite over the duration of the strategic plan

\subsection{Sensitivity analysis}

The last stage of the ORSA process consists in making a sensitivity analysis of the model to parameters so that the insurance company can identify the key drivers of insolvency. Note that it is necessary to keep in mind two essential points:

- this sensitivity analysis has first to be done on the exogenous risk factors, because this risks are well- known (therefore the analyze of the premium's uncertainty is not presented afterwards),

- the purpose of this sensitivity analysis has to be done on the risk capacity and not on the risk appetite (the risk appetite is naturally unchecked when risks increase).

As a general rule, this analyze can be done in the following way:

- by taking into account the intrinsic volatility of the estimators relative to the main risk drivers,

- on the basis of the stress tests. This second method has the advantage to allow us to use the expert judgment.

In a risk management perspective, we consider that the expert statements should be taking into account. The main risks of non-life insurance being the premium and reserve risks, we choose to analyze the evolution of the minimum coverage ratio (over the following five years):

- on the basis of stress tests which assess the impact of an increase of the reserve and combined ratio volatilities, 
- on the basis of statistical test which assess the robustness of the coverage ratio in case combined ratio value increase to the upper $95 \%$ confidence intervals bounds.

We summarize the major points of this analysis into the Table 3 (reminder the reference situation points out a minimum coverage ratio over the following five years of 130 percents).

Table 3. Sensitivity analysis

\begin{tabular}{lc}
\hline Parametring of the test & $\begin{array}{c}\text { minimum coverage } \\
\text { ratio over 5 years }\end{array}$ \\
\hline increase of $\sigma_{\beta}$ by $10 \%$ & 1.18 \\
increase of $\sigma_{\beta}$ by $20 \%$ & 1.06 \\
increase of $\sigma_{\beta}$ by $25 \%$ & 0.99 \\
increase of $\sigma_{1}$ by $10 \%$ & 1.32 \\
increase of $\sigma_{1}$ by $20 \%$ & 1.32 \\
increase of $\sigma_{1}$ by $50 \%$ & 1.30 \\
increase of $\beta$ to the upper $95 \%$ confidence intervals bounds & 0.99 \\
\hline
\end{tabular}

The Table 3 points out the robustness of the ORSA's results : the risk capacity is only outnumbered at extreme ends. The insurance company can have confidence in the capacity of the strategic plan to reflect its risk appetite.

\section{Extensions}

Below, we describe two possible extensions of the model by considering in Section 6.1 the inclusion of a premium reserve, and in Section 6.2 the presence of multiple lines of business.

\subsection{Inclusion of a Provision of Premiums}

The QIS5 (see CEIOPS [5]) provides a breakdown of the best estimate between:

- a best estimate of claims, relating to claims which already occurred as of the date of stocktaking,

- and a best estimate of premiums, relating to possible future claims arising from contracts in the portfolio at the date of inventory. The expected future premiums that these contracts will issue must therefore be considered. 
The accounting rules for future premiums are relatively complex in Solvency II. Indeed, the contract boundaries depend on the process of determining each insurer's rates. Therefore, they lead to a large heterogeneity of situations even under identical risks. In the Pillar 1 calculations, and in the context of non-life insurance used here, we take a one year horizon into account for future premiums. As in the model presented earlier in the paper, the situation is projected over several years and the only impact of not strictly complying with the rule to determine future premiums included in calculating the one year margin requirement is a lag of time in collecting the premium considered. Consequently, the absolute level of margin requirements derived from the model may be biased, but its variation is not and it is the variations of this value (and of the solvency coverage ratio) that we seek to describe.

That said, adding future premiums under Solvency II may be introduced simply by modifying the dynamics of $B E L_{t}$, defined in Section 3.1, as follows

$$
B E L_{t+1}=B E L_{t} \times X_{l}+\beta_{t+1} \times P_{t+1}+\delta \times e^{\mu} \times\left(\beta_{t+1}-1\right) \times P_{t+1},
$$

with $\delta$ the contract renewal rate and $\mu<\mu_{p}$ the annual price adjustment rate. This adjustment only has a limited effect on the model's results when the combined ratio is close to one.

\subsection{Considering Multiple Lines of Business}

In practice, one have to consider multiple lines of business leveraged by general assets, i.e., to distinguish between $B E L_{t}^{j}$ and $P_{t}^{j}$ for $j=1, \ldots, n$. In such a case, we have

$$
\chi_{t+1}=\frac{\sum_{j=1}^{n}\left(C_{t+1}^{j}+B E L_{t+1}^{j}-P_{t+1}^{j}\right)+R M_{t+1}}{1+R_{t+1}} .
$$

Therefore, we can once again use a lognormal approximation of the conditional distribution of $\chi_{t+1}$ by matching the first two moments of the numerator. The dependency between lines of business is measured by the correlation coefficients between the underlying normal distributions. This approach allows us to measure the effect of change of premiums on the mix product and to identify arbitrages in the underwriting policy. 
Denoting by $\omega_{t}$ the coefficient of variation of the variable $\sum_{j=1}^{n}\left(\left(h_{t}+\theta^{j}\right) \times B E L_{t+1}^{j}-\left(1+\beta_{t+1}^{j} \times \theta^{j}\right) \times P_{t+1}^{j}\right)$ and recalling that $V_{t}$ represents the conditional variance

$$
\omega_{t}=\frac{\sqrt{V_{t}\left(\sum_{j=1}^{n}\left(\left(h_{t}+\theta^{j}\right) \times B E L_{t+1}^{j}-\left(1+\beta_{t+1}^{j} \times \theta^{j}\right) \times P_{t+1}^{j}\right)\right)}}{\left(\sum_{j=1}^{n}\left(\left(h_{t}+\theta^{j}\right) \times B E L_{t}^{j} \times e^{\mu_{i}^{j}}-\left(1-h_{t} \times \beta^{j}\right) \times P_{t}^{j} \times e^{\mu_{p}^{j}}\right)\right)},
$$

the parameters of the lognormal approximation is then derived as

$$
\sigma_{t}^{2}=\ln \left(1+\omega_{t}^{2}\right), \mu_{t}=\ln \left(\frac{\sum_{j=1}^{n}\left(\left(h_{t}+\theta^{j}\right) \times B E L_{t}^{j} \times e^{\mu_{t}^{j}}-\left(1-h_{t} \times \beta^{j}\right) \times P_{t}^{j} \times e^{\mu_{p}^{j}}\right)}{\sqrt{1+\omega_{t}^{2}}}\right) .
$$

As in the case of a single line of business, the distribution of $\chi_{t+1}$, conditional on the information available at time $t$, is approximated by a lognormal distribution with parameters

$$
\mu_{t}(\chi)=\mu_{t}-\mu_{a}+\frac{\sigma_{a}^{2}}{2}, \sigma_{t}^{2}(\chi)=\sigma_{t}^{2}+\sigma_{a}^{2}
$$

Conforming to the QIS5 requirements, the risk margin is generally calculated by taking the SCR into account using the coefficient $h_{t}=\alpha \times \frac{S C R_{t}}{B E L_{t}} \times D_{t}$. The calculation of the variance used to evaluate $\omega_{t}$ is presented in Appendix 8.2. We also observe numerically (by broadening the scope of the example presented in Section 5) that the lognormal approximation of the variable $\chi_{t+1}$ is valid.

\section{Conclusion}

In this paper, we present a simple model to determine the distribution of the solvency coverage ratio by considering the key risk drivers (reserves, premiums and financial risk. This model allows taking into account margin requirement over the duration of the strategic plan.

Such a model used in ORSA allows measuring the impact of management choices (related to the level of premiums, asset allocations, product mix, etc.) on covering 
the insurer solvency coverage ratio. The model enables the company to assess the likelihood of non-coverage over a given horizon. In other words, the failure to comply with a minimum coverage threshold would comply internal governance. It is therefore a valuable tool for decision making. This model, which measures the effect of future production on the margin requirements and margin coverage, enters the Pillar 1 framework of Solvency II. It enables risk management to assess the regulatory solvency requirements. This approach can in particular be deployed along with the standard model as an internal model and has the advantage of being inexpensive in terms of time computation, therefore making it suitable for daily use.

\section{References}

1. Anderson T. W., Darling D. A. (1954) A Test of Goodness of Fit, JASA 49:765-69.

2. Asmussen S., Albrecher H. (2010) Ruin Probabilities (Second Edition), Advanced Series on Statistical Science and Applied Probability - Vol. 14, World Scientific.

3. Bera A, Jarque C (1980) Efficient Tests for Normality, Heteroscedasticity and Serial Independance of Regression Residuals. Economic Letter, 255-9.

4. CEIOPS (2010a) Draft proposal for Level 3 Guidelines on Own Risk and Solvency Assessment, Consultation Paper.

5. CEIOPS (2010b) QIS5 Technical Specifications, July 2010.

6. Diers D. (2009) Strategic management of assets and liabilities using multi-year internal risk models, American Risk and Insurance Association, Meeting Paper.

7. Dufresne D. (2004) The log-normal approximation in financial and other applications, Adv. Appl. Prob., 36, (747-773).

8. El Faouzi N.E; Maurin M (2006) Sur la loi de la somme de variables log-normales : application à la fiabilité de temps de parcours routiers, Working Paper, INRETS.

9. Fenton L. F. (1960) The sum of log-normal probability distributions in scattered transmissions systems, IRE Trans. Commun. System, 8, (57-67).

10. Guibert Q, Juillard M, Planchet F (2010) Un cadre de référence pour un modèle interne partiel en assurance de personnes, Bulletin Français d'Actuariat 10(20).

11. Liebwein P. (2006) Risk Models for Capital Adequacy: Applications in the Context of Solvency II and Beyond, The Geneva Papers, 2006, 31, (528-550).

12. Planchet F, Juillard M (2010) Le Pilier 2 : du calcul de l'exigence de marge au pilotage d'un profil de risqué, la Tribune de l'Assurance (rubrique « le mot de l'actuaire ») (153), 01/12/2010.

13. R Development Core Team (2011), R: A Language and Environment for Statistical Computting, R Foundation for Statistical Computing, Vienna, Austria. URL: http://www.Rproject.org.

14. Robert C.Y. (2011) Market Value Margin calculations under the Cost of Capital approach within a Bayesian chain ladder framework, ISFA, Working Paper.

15. Saporta G (1990) Probabilités, analyse des données et statistique, Technip.

16. Schwartz S. (1982) On the distribution function and moments of power sums of with lognormal components, Bell Syst. Tech J., 1982, 61, (1441-1462). 


\section{Appendix}

The calculation of the moments of the variable $\chi_{t+1}$ is presented in this Section for one or more lines of business.

\subsection{For one line of business}

Upstream of the presentation of the multiple- lines of business, we start by introducing the calculation of the moments of the variable $\chi_{t+1}$ in the presence of only one line of business.

Thanks to the following expression

$$
\begin{aligned}
\left(h_{t}+\theta\right) \times B E L_{t+1}-\left(1+\theta \times \beta_{t+1}\right) \times P_{t+1} & =\left(h_{t}+\theta\right) \times B E L_{t} \times e^{\mu_{l}-\frac{\sigma_{l}^{2}}{2}+\sigma_{l} \times \varepsilon_{t+1, l}}, \\
& -\left(1-h_{t} \times \beta_{t+1}\right) \times P_{t+1}
\end{aligned},
$$

we find the value of the conditional expectancy

$$
\begin{aligned}
E_{t}\left(\left(h_{t}+\theta\right) \times B E L_{t+1}-\left(1+\theta \times \beta_{t+1}\right) \times P_{t+1}\right) & =\left(h_{t}+\theta\right) \times B E L_{t} \times e^{\mu_{t}} \\
& -\left(1-h_{t} \times \beta\right) \times P_{t} \times e^{\mu_{p}} .
\end{aligned}
$$

Also, given that $\varepsilon_{t+1, \beta}, \varepsilon_{t+1, p}, \varepsilon_{t+1, l}$ are independent, we have the conditional variance

$$
\begin{aligned}
& V_{t}\left(\left(h_{t}+\theta\right) \times B E L_{t+1}-\left(1+\theta \times \beta_{t+1}\right) \times P_{t+1}\right) \\
& =V_{t}\left(\left(h_{t}+\theta\right) \times B E L_{t} \times e^{\mu_{l}-\frac{\sigma_{l}^{2}}{2}+\sigma_{l} \times \varepsilon_{t+1, t}}-\left(1-h_{t} \times \beta_{t+1}\right) \times P_{t+1}\right) \\
& =\left(h_{t}+\theta\right)^{2} \times B E L_{t}^{2} \times e^{2 \mu_{l}} \times\left(e^{\sigma_{l}^{2}}-1\right)+h_{t}^{2} \times \beta^{2} \times\left(e^{\sigma_{\beta}^{2}}-1\right) \times P_{t}^{2} \times e^{2 \mu_{p}} \times\left(e^{\sigma_{p}^{2}}-1\right), \\
& +h_{t}^{2} \times \beta^{2} \times\left(e^{\sigma_{\beta}^{2}}-1\right) \times P_{t}^{2} \times e^{2 \mu_{p}}+P_{t}^{2} \times e^{2 \mu_{p}} \times\left(e^{\sigma_{p}^{2}}-1\right) \times\left(1-h_{t} \times \beta\right)^{2} \\
& =\left(h_{t}+\theta\right)^{2} \times B E L_{t}^{2} \times e^{2 \mu_{l}} \times\left(e^{\sigma_{l}^{2}}-1\right)+h_{t}^{2} \times \beta^{2} \times\left(e^{\sigma_{\beta}^{2}}-1\right) \times P_{t}^{2} \times e^{2 \mu_{p}+\sigma_{p}^{2}} \\
& +P_{t}^{2} \times e^{2 \mu_{p}} \times\left(e^{\sigma_{p}^{2}}-1\right) \times\left(1-h_{t} \times \beta\right)^{2}
\end{aligned}
$$

and thus, we deduce of (5) the coefficient of variation of $\left(h_{t}+\theta\right) \times B E L_{t+1}-\left(1+\theta \times \beta_{t+1}\right) \times P_{t+1}$ is 


$$
\omega_{t}=\frac{\sqrt{\left(h_{t}+\theta\right)^{2} \times B E L_{t}^{2} \times e^{2 \mu_{l}} \times\left(e^{\sigma_{l}^{2}}-1\right)+h_{t}^{2} \times \beta^{2} \times\left(e^{\sigma_{\beta}^{2}}-1\right) \times P_{t}^{2} \times e^{2 \mu_{p}+\sigma_{p}^{2}}}}{\left(P_{t}^{2} \times e^{2 \mu_{p}} \times\left(e^{\sigma_{p}^{2}}-1\right) \times\left(1-h_{t} \times \beta\right)^{2}\right.} .
$$

\subsection{For several lines of business}

We continue with model containing several lines of business supposing the lognormal approximation is validated. First, we calculate the first two moments of the numerator of $\chi_{t+1}$, and then we deduce those of $\chi_{t+1}$. We have calculated the conditional expectation of the variable $\sum_{j=1}^{n}\left(\left(h_{t}+\theta^{j}\right) \times B E L_{t+1}^{j}-\left(1+\beta_{t+1}^{j} \times \theta^{j}\right) \times P_{t+1}^{j}\right)$

$$
\begin{aligned}
& E_{t}\left(\sum_{j=1}^{n}\left(\left(h_{t}+\theta^{j}\right) \times B E L_{t+1}^{j}-\left(1+\beta_{t+1}^{j} \times \theta^{j}\right) \times P_{t+1}^{j}\right)\right) \\
& =\sum_{j=1}^{n}\left(E_{t}\left(\left(h_{t}+\theta^{j}\right) \times B E L_{t+1}^{j}-\left(1+\beta_{t+1}^{j} \times \theta^{j}\right) \times P_{t+1}^{j}\right)\right), \\
& =\sum_{j=1}^{n}\left(\left(h_{t}+\theta^{j}\right) \times B E L_{t}^{j} \times e^{\mu_{t}^{j}}-\left(1-h_{t} \times \beta^{j}\right) \times P_{t}^{j} \times e^{\mu_{p}^{j}}\right)
\end{aligned}
$$

and its conditional variance

$$
\begin{aligned}
& V_{t}\left(\sum_{j=1}^{n}\left(\left(h_{t}+\theta^{j}\right) \times B E L_{t+1}^{j}-\left(1+\beta_{t+1}^{j} \times \theta^{j}\right) \times P_{t+1}^{j}\right)\right) \\
& =\sum_{j=1}^{n}\left(V_{t}\left(\left(h_{t}+\theta^{j}\right) \times B E L_{t+1}^{j}-\left(1+\beta_{t+1}^{j} \times \theta^{j}\right) \times P_{t+1}^{j}\right)\right) \\
& +2 \sum_{1 \leq i<j \leq n} \operatorname{Cov}_{t}\left(\left(h_{t}+\theta^{i}\right) \times B E L_{t+1}^{i}-\left(1+\beta_{t+1}^{i} \times \theta^{i}\right) \times P_{t+1}^{i},\left(h_{t}+\theta^{j}\right) \times B E L_{t+1}^{j}-\left(1+\beta_{t+1}^{j} \times \theta^{j}\right) \times P_{t+1}^{j}\right)
\end{aligned}
$$

The first component of the conditional variance is obtained simply

$$
\begin{aligned}
& \sum_{j=1}^{n}\left(V_{t}\left(\left(h_{t}+\theta^{j}\right) \times B E L_{t+1}^{j}-\left(1+\beta_{t+1}^{j} \times \theta^{j}\right) \times P_{t+1}^{j}\right)\right) \\
& =\sum_{j=1}^{n}\left(\begin{array}{l}
\left(h_{t}+\theta^{j}\right)^{2} \times B E L_{t}^{j 2} \times e^{2 \mu_{i}^{j}} \times\left(e^{\sigma_{l}^{j 2}}-1\right) \\
+P_{t}^{j 2} \times e^{2 \mu_{p}^{j}} \times\left(h_{t}^{2} \times \beta^{j 2} \times\left(e^{\left(\sigma_{p}^{j 2}+\sigma_{\beta}^{j 2}\right)}-1\right)+\left(e^{\sigma_{p}^{j 2}}-1\right)\left(1-2 h_{t} \times \beta^{j}\right)\right)
\end{array}\right) .
\end{aligned}
$$

The second term is obtained by noting that the covariance of the two random lognormal variables $\left(Y_{1}, Y_{2}\right)$ with parameters $\left(\mu_{1}, \sigma_{1}\right)$ and $\left(\mu_{2}, \sigma_{2}\right)$, respectively, are obtained from the covariance of the underlying normal variables $\left(\varepsilon_{1}, \varepsilon_{2}\right)$ 


$$
\operatorname{Cov}\left(Y_{1}, Y_{2}\right)=E\left(Y_{1}\right) \times E\left(Y_{2}\right)\left(e^{\operatorname{Cov}\left(\varepsilon_{1}, \varepsilon_{2}\right)}-1\right)
$$

Denoting that the correlation coefficients $\rho_{l}^{i j}, \rho_{p}^{i j}$ and $\rho_{\beta}^{i j}$ are associated with the variables $\left(B E L_{t}^{i}, B E L_{t}^{j}\right),\left(C_{t}^{i}, C_{t}^{j}\right)$ and $\left(\beta_{t}^{i}, \beta_{t}^{j}\right)$, respectively, we get

$$
\begin{aligned}
& \operatorname{Cov}_{t}\left(\left(h_{t}+\theta^{i}\right) \times B E L_{t+1}^{i}-\left(1+\beta_{t+1}^{i} \times \theta^{i}\right) \times P_{t+1}^{i},\left(h_{t}+\theta^{j}\right) \times B E L_{t+1}^{j}-\left(1+\beta_{t+1}^{j} \times \theta^{j}\right) \times P_{t+1}^{j}\right) \\
& =\left(h_{t}+\theta^{i}\right)\left(h_{t}+\theta^{j}\right) \times B E L_{t}^{i} \times B E L_{t}^{j} \times e^{\mu_{l}^{i}+\mu_{l}^{j}} \times\left(e^{\rho_{l}^{i j} \sigma_{l}^{i} \sigma_{l}^{j}}-1\right) \\
& +h_{t}^{2} \times \operatorname{Cov}_{t}\left(\beta_{t+1}^{i} \times P_{t+1}^{i}, \beta_{t+1}^{j} \times P_{t+1}^{j}\right)-h_{t} \times \operatorname{Cov}_{t}\left(\beta_{t+1}^{i} \times P_{t+1}^{i}, P_{t+1}^{j}\right) \\
& -h_{t} \times \operatorname{Cov}_{t}\left(\beta_{t+1}^{j} \times P_{t+1}^{j}, P_{t+1}^{i}\right)+\operatorname{Cov}_{t}\left(P_{t+1}^{i}, P_{t+1}^{j}\right)
\end{aligned}
$$

But we have

$$
\begin{aligned}
\operatorname{Cov}_{t}\left(P_{t+1}^{i}, P_{t+1}^{j}\right) & =P_{t}^{i} \times P_{t}^{j} \times e^{\mu_{p}^{i}+\mu_{p}^{j}} \times\left(e^{\rho_{p}^{i j} \sigma_{p}^{i} \sigma_{p}^{j}}-1\right), \\
\operatorname{Cov}_{t}\left(P_{t+1}^{i}, \beta_{t+1}^{j} \times P_{t+1}^{j}\right) & =E_{t}\left(\beta_{t+1}^{j}\right) \times \operatorname{Cov}_{t}\left(P_{t+1}^{i}, P_{t+1}^{j}\right) \\
& =\beta^{j} \times P_{t}^{i} \times P_{t}^{j} \times e^{\mu_{p}^{i}+\mu_{p}^{j}} \times\left(e^{\rho_{p}^{i j} \sigma_{p}^{i} \sigma_{p}^{j}}-1\right),
\end{aligned}
$$

And

$$
\begin{aligned}
& \operatorname{Cov}_{t}\left(\beta_{t+1}^{i} \times P_{t+1}^{i}, \beta_{t+1}^{j} \times P_{t+1}^{j}\right) \\
& =E_{t}\left(\beta_{t+1}^{i}\right) \times E_{t}\left(\beta_{t+1}^{j}\right) \times \operatorname{Cov}_{t}\left(P_{t+1}^{i}, P_{t+1}^{j}\right)+E_{t}\left(P_{t+1}^{i}\right) \times E_{t}\left(P_{t+1}^{j}\right) \times \operatorname{Cov}_{t}\left(\beta_{t+1}^{i}, \beta_{t+1}^{j}\right) . \\
& =\beta^{i} \times \beta^{j} \times P_{t}^{i} \times P_{t}^{j} \times e^{\mu_{p}^{i}+\mu_{p}^{j}}\left(e^{\rho_{p}^{i j} \sigma_{p}^{i} \sigma_{p}^{j}+\rho_{\beta}^{i j} \sigma_{\beta}^{i} \sigma_{\beta}^{j}}-1\right)
\end{aligned}
$$

We then deduce

$$
\begin{aligned}
& \operatorname{Cov}_{t}\left(\left(h_{t}+\theta^{i}\right) \times B E L_{t+1}^{i}-\left(1+\beta_{t+1}^{i} \times \theta^{i}\right) \times P_{t+1}^{i},\left(h_{t}+\theta^{j}\right) \times B E L_{t+1}^{j}-\left(1+\beta_{t+1}^{j} \times \theta^{j}\right) \times P_{t+1}^{j}\right) \\
& =\left(h_{t}+\theta^{i}\right)\left(h_{t}+\theta^{j}\right) \times B E L_{t}^{i} \times B E L_{t}^{j} \times e^{\mu_{t}^{i}+\mu_{l}^{j}} \times\left(e^{\rho_{l}^{j} \sigma_{t}^{i} \sigma_{l}^{j}}-1\right) \\
& +P_{t}^{i} \times P_{t}^{j} \times e^{\mu_{p}^{i}+\mu_{p}^{j}}\left[\begin{array}{l}
h_{t}^{2} \times \beta^{i} \times \beta^{j} \times\left(e^{\rho_{p}^{i} \sigma_{p}^{i} \sigma_{p}^{j}+\rho_{\beta}^{i j} \sigma_{\beta}^{i} \sigma_{\beta}^{j}}-1\right) \\
+\left(e^{\rho_{p}^{j} \sigma_{p}^{i} \sigma_{p}^{j}}-1\right)\left(1-h_{t} \times\left(\beta^{i}+\beta^{j}\right)\right)
\end{array}\right]
\end{aligned} .
$$

We finally infer the coefficient of variation of $\sum_{j=1}^{n}\left(\left(h_{t}+\theta^{j}\right) \times B E L_{t+1}^{j}-\left(1+\beta_{t+1}^{j} \times \theta^{j}\right) \times P_{t+1}^{j}\right)$ 


$$
\omega_{t}=\frac{\sqrt{V_{t}\left(\sum_{j=1}^{n}\left(\left(h_{t}+\theta^{j}\right) \times B E L_{t+1}^{j}-\left(1+\beta_{t+1}^{j} \times \theta^{j}\right) \times P_{t+1}^{j}\right)\right)}}{\left(\sum_{j=1}^{n}\left(\left(h_{t}+\theta^{j}\right) \times B E L_{t}^{j} \times e^{\mu_{i}^{j}}-\left(1-h_{t} \times \beta^{j}\right) \times P_{t}^{j} \times e^{\mu_{p}^{j}}\right)\right)},
$$

and then the parameters of the lognormal approximation

$$
\sigma_{t}^{2}=\ln \left(1+\omega_{t}^{2}\right), \mu_{t}=\ln \left(\frac{\sum_{j=1}^{n}\left(\left(h_{t}+\theta^{j}\right) \times B E L_{t}^{j} \times e^{\mu_{i}^{j}}-\left(1-h_{t} \times \beta^{j}\right) \times P_{t}^{j} \times e^{\mu_{p}^{j}}\right)}{\sqrt{1+\omega_{t}^{2}}}\right) .
$$

As in the case of a single line of business (see Section 8.1), the distribution of $\chi_{t+1}$ conditional on the information available at time $t$ is approximated by a lognormal distribution with parameters

$$
\mu_{t}(\chi)=\mu_{t}-\mu_{a}+\frac{\sigma_{a}^{2}}{2}, \sigma_{t}^{2}(\chi)=\sigma_{t}^{2}+\sigma_{a}^{2}
$$

